\title{
A Comparative Study the Calculation of the Optical Gap Energy and Urbach Energy in Undoped and Indium Doped ZnO Thin Films
}

\author{
Said Benramache1,*, Boubaker Benhaoua², Okba Belahssen ${ }^{1}$ \\ ${ }^{1}$ Material Sciences Department, Faculty of Science, University of Biskra, Biskra 07000 Algeria \\ 2 VTRS Laboratory, Institute of Technology, University of El-Oued, El-Oued, Algeria
}

(Received 29 November 2015; published online 15 March 2016)

\begin{abstract}
In the present paper, we investigated a new model by theoretical methods; it is based on correlation from the experimental data's which was used in the calculation the optical gap energy and Urbach energies. These data's were taken from papers previously published. The choice ZnO thin films and spray only to compare our models with the Indium doping. From obtained relations found that the experimental data and theoretical calculation are in qualitative, which were supported with the variation of solution molarities and Indium doping. We have obtained a high correlation coefficient in the estimation of the band gap energy is higher than 0.96 with compare of Urbach energy is changed from 0.84 to 0.89 . The measurements by these new models have agreed with minimum relative errors, it is found in the calculations of optical band gap does not exceed $4 \%$, and for Urbach energy are smaller than 20 and $10 \%$ for undoped and Indium doped $\mathrm{ZnO}$ films, respectively. So that the best estimation was found at the Indium doped $\mathrm{ZnO}$ thin with maximum enhancement of minimum errors were limited to 3.5 and $9.7 \%$ for the band gap and the Urbach energies, respectively. The decreases in the relative errors of undoped to Indium doped films can be explained by the fewer defects and less disorder.
\end{abstract}

Keywords: $\mathrm{ZnO}$, Thin film, Semiconductor doping, Calculation.

PACS numbers: 02.30.Vv, 68.55.ag, 78.20.Bh,

81.40.Tv

\section{INTRODUCTION}

Over the past decades, rapid research and developments have been made in the field of metal oxide nanostructures because of their unique properties that can be used in an array of applications for the production of novel and efficient nanodevices. Among various metal oxides, Zinc oxide $(\mathrm{ZnO})$ which is one of the most important materials in the synthesis of solar cell applications has good optical properties which can observe in the fewer defects and less disorder. The semiconductor compounds as a $\mathrm{ZnO}$ has a $n$-type good electrical conductivity with a direct energy wide band gap of $3.37 \mathrm{eV}$ at room temperature, a large exciton binding energy ( $60 \mathrm{meV}$ ) [1-4].

Oxide metals as a $\mathrm{ZnO}$ have gained much interest in science and technology due to their interesting applications such as transparent conductive, ferromagnetism, semiconductors, piezoelectric and solar cells, Indium doped $\mathrm{ZnO}$ thin films have low resistivity and good optical gap energy at low deposition [5-8].

Several techniques can be used to prepare $\mathrm{ZnO}$ as a thin film among them reactive evaporation and thermal annealing [9], molecular beam epitaxy (MBE) [10], magnetron sputtered technique [11], pulsed laser deposition (PLD) [12], the low-temperature solution method [13], potentiostatic and electrodeposition [14], the sol-gel technique [15], chemical vapor deposition, electrochemical deposition [16] and spray pyrolysis [17], The choice of undoped and Indium doped $\mathrm{ZnO}$ thin films deposited by same spray techniques in this work because of its good results, There are many reliable results can be used to reduce errors after modeling.
In this paper, the experimental datas of undoped and Indium doped $\mathrm{ZnO}$ thin films were taken from papers previously published. The estimation the optical gap energy Eg and Urbach energy Eu of these materials can be correlated with solution molarity and Indium doping.

\section{EXPERIMENTAL AND METHODS}

In this work, the experimental datas of undoped and Indium doped $\mathrm{ZnO}$ thin films such as the optical gap energy and Urbach energy were taken from papers previously published [18-28] they studied the effect of solution molarity, doping level and substrate temperature on structural, optical and electrical properties of $\mathrm{ZnO}$ thin films (see Table 1). Table 1, shows the preparation conditions were chosen to investigate in the theoretical methods as can be seen, each samples were deposited using spray techniques on glass substrates at a temperature of $350{ }^{\circ} \mathrm{C}$. In the analysis of the variations of optical gap energy and Urbach energy of undoped and Indium doped $\mathrm{ZnO}$ thin films can be varied in the form nonlinear (see Tables 2 and 3). The model proposed to calculate with solution molarity and doping level is discussed. In this study, we will show that the effect of doping level on the correlation of optical gap energy and Urbach energy, we tried to establish correlations for each model proposed.

\section{THEORETICAL CALCULATIONS}

\subsection{Undoped ZnO Thin Films}

Firstly, the primary model was used for correlation of the optical gap energy between the Urbach energy

\footnotetext{
*benramache.said@gmail.com
} 
and solution molarity in the undoped $\mathrm{ZnO}$ thin films, this relationship can write in the form nonlinear, as expressed in our published paper [29]:

$$
E_{\text {gcor. }}=(3.28711) \times\left(\frac{M}{E_{u}}\right)^{0.0184683} \text { if } X_{0}=0
$$

where $E_{u}$ is the Urbach energy, $M$ is the solution molarity $E_{\text {gcor }}$. is the estimate of optical gap energy and $a$ and $b$ are empirical constants as $a \approx 3.28711$ and $b \approx 0.0184683$ are shown in Table 2 . On the other hand, the Urbach energy of undoped $\mathrm{ZnO}$ thin films can be developed with solution molarity, it was related with the optical gap energy, which was obtained in the following formula:

$$
E_{u}=\exp \left(\ln \mathrm{M}+\frac{1}{\mathrm{~b}} \ln \frac{a}{E_{g}}\right) \pm \Delta \mathrm{E}_{\mathrm{u}} \text { if } X_{0}=0
$$

where $a, b$ are empirical constants were related of the undoped as $a \approx 3.28711$ and $b \approx 0.0184683$ (see Eq. (1)). These constants were measured in the section 3.1 and 3.2. The resulting errors $\left(\Delta E_{u}\right)$ was calculated from Eq. (1), which was called the pass value of optical gap energy to Urbach energy as shown in the following proposal:

$$
\Delta E_{u}=\frac{1}{b} \frac{\Delta E_{g}}{E_{g}} E_{u}
$$

\subsection{Indium Doped ZnO Thin Films}

In the Indium doped $\mathrm{ZnO}$ films, here the correlation to calculate the optical gap and Urbach energies were based on Eq.(1) and (2), respectively, with introduce the 0 wt. $\%$, to perform the correlation in this step the optical parameters were measured with doping levels. The correlation can be written in another form such following relation:

$$
\begin{aligned}
& E_{g}=\left(3.28711 \times\left(1+A X_{0}\right)\right) \times\left(\frac{M}{E_{u}}\right)^{\left(0.0184683 \times\left(1+B X_{0}\right)\right)} \\
& \text { if } X_{0} \succ 0 \\
& E_{u}=\exp \left(\ln M+\frac{1}{b\left(1+B X_{0}\right)} \ln \frac{a\left(1+A X_{0}\right)}{E_{g}}\right) \pm \Delta E_{u} \\
& \text { if } X_{0} \succ 0
\end{aligned}
$$

where $a, b$ and $A, B$ are empirical constants were related of the undoped and Indium doped thin films, respectively, and $X_{0}$ is the Indium concentration in doped $\mathrm{ZnO}$ films. These constants were measured from Eq.(1) and (4), respectively. The resulting errors $\left(\Delta E_{u}\right)$ in the Indium doped $\mathrm{ZnO}$ films was calculated from Eq. (4) as shown in the following proposal:

$$
\Delta E_{u}=\frac{1}{\left(b\left(1+B X_{0}\right)\right)} \frac{\Delta E_{g}}{E_{g}} E_{u}
$$

\subsection{The Relative Error Measurement}

The relative error values for our correlation were measured between the experimental data and correlate values by the following relationships:

$$
\begin{aligned}
& \varepsilon=\left|\left(E_{g E x p}-E_{g C o r r}\right) / E_{g E x p}\right| \times 100 \\
& \varepsilon=\left|\left(E_{u E x p}-E_{u C o r r}\right) / E_{u E x p}\right| \times 100
\end{aligned}
$$

\begin{tabular}{|c|c|c|c|c|c|c|c|c|c|}
\hline \multicolumn{10}{|c|}{ Undoped $\mathrm{ZnO}$ thin films $a \approx 3.28711$ and $b \approx 0.0184683$} \\
\hline S.N. & $\begin{array}{c}M \\
(\mathrm{~mol} .1-1)\end{array}$ & $T\left({ }^{\circ} \mathrm{C}\right)$ & $\begin{array}{c}E_{g} \text { (Exp.) } \\
(\mathrm{eV})\end{array}$ & $E_{u}(\mathrm{eV})$ & $\begin{array}{c}E_{g} \text { (Corr.) } \\
(\mathrm{eV})\end{array}$ & Error (\%) & $\begin{array}{c}E_{u} \text { (Corr.) } \\
(\mathrm{eV})\end{array}$ & Error (\%) & Ref \\
\hline 1 & 0.05 & 350 & 3.08 & 0.9221 & 3.115 & 1.136 & 0.938 & 1.72 & [18] \\
\hline 2 & 0.075 & 350 & 3.22 & 0.3186 & 3.200 & 0.590 & 0.281 & 11.80 & [18] \\
\hline 3 & 0.1 & 350 & 3.37 & 0.085 & 3.297 & 2.166 & 0.069 & 18.82 & [18] \\
\hline 4 & 0.125 & 350 & 3.15 & 0.1757 & 3.266 & 3.682 & 0.201 & 14.39 & [18] \\
\hline 5 & 0.1 & 350 & 3.10 & 0.2734 & 3.212 & 3.612 & 0.279 & 2.05 & [19] \\
\hline 6 & 0.1 & 350 & 3.267 & 0.108 & 3.273 & 0.183 & 0.108 & 0 & [20] \\
\hline 7 & 0.02 & 350 & 3.19 & 0.08 & 3.204 & 0.439 & 0.071 & 11.25 & [21] \\
\hline 8 & 0.1 & 350 & 3.25 & 0.064 & 3.314 & 1.969 & 0.074 & 15.62 & {$[22]$} \\
\hline 9 & 0.1 & 350 & 3.304 & 0.1139 & 3.279 & 0.757 & 0.101 & 11.32 & [23] \\
\hline 10 & 0.1 & 350 & 3.317 & 0.0983 & 3.288 & 0.874 & 0.097 & 1.32 & [24] \\
\hline 11 & 0.1 & 350 & 3.27 & 0.17 & 3.255 & 0.458 & 0.165 & 2.94 & [25] \\
\hline 12 & 0.1 & 350 & 3.25 & 0.209 & 3.243 & 0.215 & 0.203 & 2.87 & [26] \\
\hline 13 & 0.1 & 350 & 3.23 & 0.490 & 3.192 & 1.176 & 0.444 & 9.39 & [27] \\
\hline
\end{tabular}

Table 1-The parameters conditions were used in this research

\begin{tabular}{|l|l|}
\hline Method & Ultrasonic Spray or spray pyrolysis \\
\hline Oxide & Zinc oxide thin films \\
\hline Zn reactants & Zn acetate or ZnCl2 \\
\hline Solvents & Ethanol-methanol-water \\
\hline Substrate & Glass \\
\hline Molarity (M) & $0.02-0.05-0.075-0.1-0.125$ \\
\hline Temperature $\left(^{\circ}\right)$ & $300,350,360,400,410,450$ \\
\hline dopant & In \\
\hline$[\operatorname{In}] /[\mathrm{Zn}](\%)$ & 1 to 15 \\
\hline
\end{tabular}

Table 2 - Summary results of experimental data, the correlate optical gap energy, the correlate Urbach energy and relative errors for the Undoped $\mathrm{ZnO}$ thin films 
Table 3 - Summary results of experimental data, the correlate optical gap energy, the correlate Urbach energy and relative errors for the Indium doped $\mathrm{ZnO}$ thin films

\begin{tabular}{|c|c|c|c|c|c|c|c|c|c|}
\hline \multicolumn{9}{|c|}{ In doped $\mathrm{ZnO}$ thin films with $0.1 \mathrm{~mol} . \mathrm{l}-1$} & \\
\hline S.N. & \begin{tabular}{|l}
$\mathrm{X}] /[\mathrm{Zn}]$ \\
$(\%)$
\end{tabular} & \begin{tabular}{|l|}
$\mathrm{T}$ \\
$\left({ }^{\circ} \mathrm{C}\right)$
\end{tabular} & $\begin{array}{l}E_{g}(\text { Exp. }) \\
(\mathrm{eV})\end{array}$ & $\begin{array}{l}E_{u} \\
(\mathrm{eV})\end{array}$ & $\begin{array}{l}E_{g} \text { (Corr.) } \\
(\mathrm{eV})\end{array}$ & $\begin{array}{l}\text { Error } \\
(\%)\end{array}$ & $\begin{array}{l}E_{u} \text { (Corr.) } \\
(\mathrm{eV})\end{array}$ & \begin{tabular}{|l} 
Error \\
$(\%)$
\end{tabular} & Ref. \\
\hline 1 & 0 & 350 & 3.23 & 0.490 & 3.192 & 1.176 & 0.466 & 4.89 & \multirow{5}{*}[27]{} \\
\hline 2 & 2 & 350 & 3.22 & 0.295 & 3.275 & 1.708 & 0.304 & 3.05 & \\
\hline 3 & 4 & 350 & 3.26 & 0.288 & 3.316 & 1.717 & 0.316 & 9.72 & \\
\hline 4 & 6 & 350 & 3.41 & 0.285 & 3.335 & 2.199 & 0.276 & 3.15 & \\
\hline 5 & 8 & 350 & 3.41 & 0.285 & 3.328 & 2.404 & 0.279 & 2.10 & \\
\hline 6 & 0 & 350 & 3.25 & 0.209 & 3.243 & 0.215 & 0.189 & 9.56 & \multirow{4}{*}[28]{} \\
\hline 7 & 2 & 350 & 3.158 & 0.423 & 3.170 & 0.379 & 0.395 & 6.62 & \\
\hline 8 & 3 & 350 & 3.185 & 0.328 & 3.248 & 1.978 & 0.352 & 7.31 & \\
\hline 9 & 4 & 350 & 3.067 & 0.376 & 3.174 & 3.488 & 0.402 & 6.91 & \\
\hline
\end{tabular}
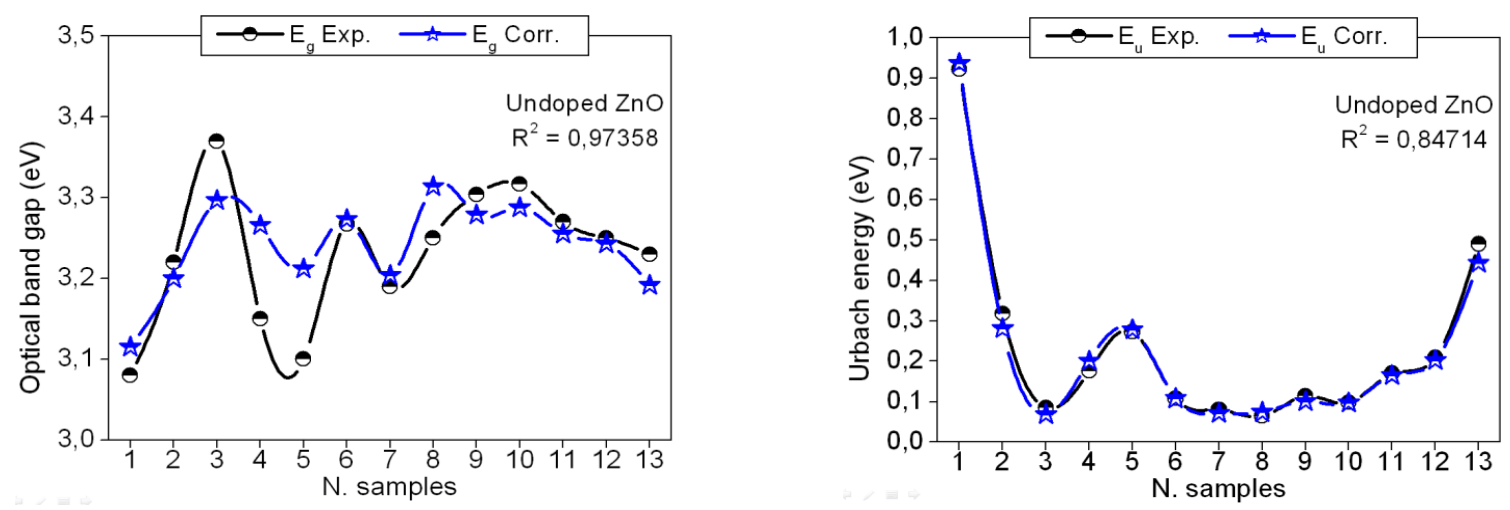

Fig. 1 - The variation of optical gap energy and Urbach energy experimental and correlate of Undoped ZnO thin films
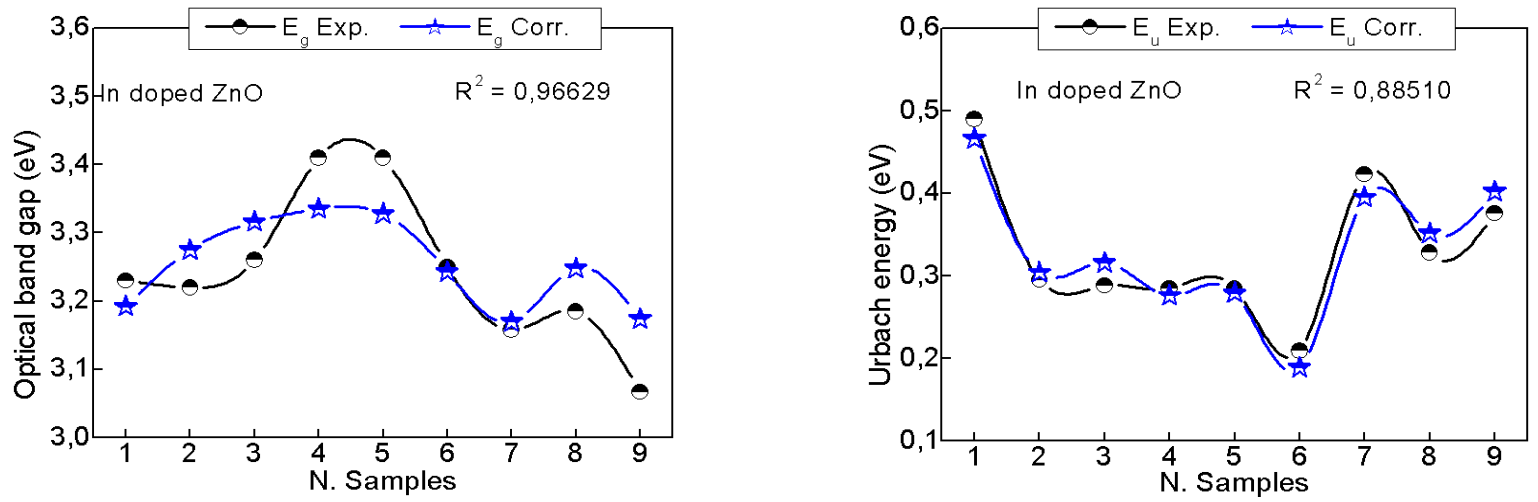

Fig. 2 - The variation of optical gap energy and Urbach energy experimental and correlate of Indium doped ZnO thin films

where $E_{g(e)}, E_{u(e)}$ and $E_{g(c)}, E_{u(c)}$ are the experimental and correlate values of optical gap energy and Urbach energy, respectively, $\varepsilon$ is the relative error.

\section{RESULTS AND DISCUSSION}

Figure 1, shows the variation of optical gap energy and Urbach energy experimental and correlate for Undoped $\mathrm{ZnO}$ thin films, The values of the scaled parameters were calculated according to Eq. (1) and Eq. (2), as presents in Table 2, there were estimated as a function of solution molarity and their energies, As can be seen, all measured values of the optical energy gap is inversely proportional to the Urbach energy. From these figures can be found that all correlation values are proportional to the experimental data's. So found a high correlation coefficient in the estimation of the band gap energy and Urbach energy are 0.97358 and 0.84714 , respectively, which the maximum agreement of the estimation was found to be minimum error.

As shown in Figures 2, significant the doping evolution of Indium doped $\mathrm{ZnO}$ thin films on their optical gap and Urbach energies. here the investigations were carried out of the Eq. (1) and Eq. (2), as presents in Table 3, As can be seen, with comparing with undoped the Indium doping has a high correlation coefficient to estimate of the band gap energy and Urbach energy were 0.96629 and 0.88510 , respectively, It can also say that the calculations values are in qualitative agreements with the experimental data, which the maximum agreement of the estimation was found to be minimum relative error. The correlation coefficient depends on both relative errors and doping via: 


$$
R=1-\frac{\sum_{i}^{N} \varepsilon_{i}}{N}
$$

where $N$ is the number of measurement and $\varepsilon$ is the relative error. The correlation coefficients are presents in Figures 1 and 2, it can be seen that the Indium doped $\mathrm{ZnO}$ thin films has a good and achieved results obtaining from increasing the correlation coefficients, this is the approach we have adopted in the enhance of band gap energy and less disorder of $\mathrm{ZnO}$ thin films with doping.
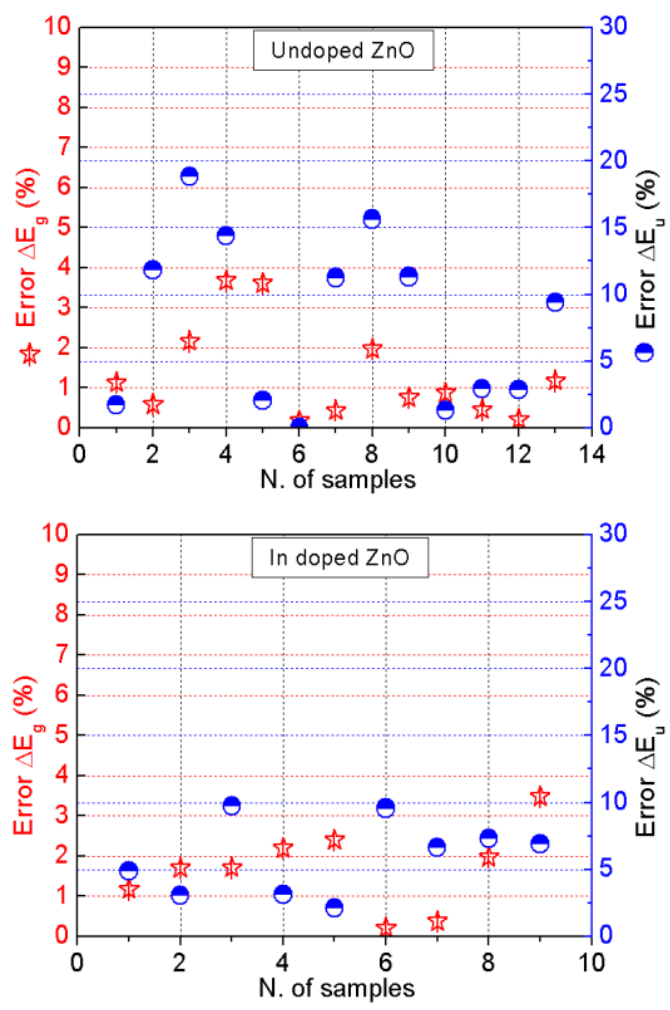

Fig. 3 - The correlation coefficients for optical gap energy and Urbach energy at different dopant's

\section{REFERENCES}

1. S. Benramache, S. Gareh, B. Benhaoua, A. Darsouni, O. Belahssen, J. Chem. Mater. Res. 2 No 2, 59 (2015).

2. M. Benhaliliba, Y.S. Ocak, H. Mokhtari, T. Kiliçoglu, J. Nano-Electron. Phys. 7 No 2, 02001 (2015).

3. P.K. Samanta, A. Saha, T. Kamilya, J. Nano- Electron. Phys. 6 No 4, 04015 (2015).

4. N.P. Klochko, G.S. Khrypunov, Y.O. Myagchenko, E.E. Melnychuk, V.R. Kopach, K.S. Klepikova, V.M. Lyubov, A.V. Kopach, J. Nano- Electron. Phys. 6 No 4, 04030 (2015).

5. A.D. Pogrebnjak, T.O. Berestok, A.S. Opanasyuk, Y. Takeda, K. Oyoshi, F.F. Komarov, J. Kassi, J. NanoElectron. Phys. 6 No 2, 02003 (2014).

6. M. Benhaliliba, Y.S. Ocak, A. Tab, J. Nano- Electron. Phys. 5 No 3, 03001 (2013).

7. Y. Aoun, B. Benhaoua, B. Gasmi, S. Benramache, Main Group Chemi. 14 No 1, 27 (2015).

8. S. Aydemir, S. Karakaya, Optik 126 No 18, 1735 (2015).

9. D. Chhikara, M.S. Kumar, K.M.K. Srivatsa, Superlattices Microstruct. 82, 368 (2014).
The maximum enhancement of the correlation coefficients values were estimated for the optical gap energy values (see Tables 2 and 3).

In the Figures 3, we obtained that the relative errors of our correlations of undoped and Indium doped $\mathrm{ZnO}$ thin films. For the optical gap energy all calculation are smaller than $4 \%$, however, we found after calculate the relative error of the Urbach energies are improved which the maximum enhancement of minimum error was found at Indium doped $\mathrm{ZnO}$ thin films do not exceed $10 \%$. It were confirmed that these models are suitable for calculations of optical properties with varying of some parameters. The decreases in the relative errors of undoped to doped films can be explained by the good optical properties which can observe in the fewer defects and less disorder.

\section{CONCLUSION}

In summary, the undoped and Indium doped $\mathrm{ZnO}$ thin films were deposited at different precursor molarities by ultrasonic spray and spray pyrolysis techniques. The relation between the experimental data and theoretical calculation were investigated. The measurements by these proposals models are in qualitative agreements with the experimental data, which were supported with the variation of solution molarities and Indium doping. We have obtained a high correlation coefficient in the estimation of the band gap energy is higher than 0.96 with compare of Urbach energy is changed from 0.84 to 0.89 . The measurements by these new models have agreed with minimum relative errors, it is found in the calculations of optical band gap does not exceed $4 \%$, and for Urbach energy are smaller than 20 and $10 \%$ for undoped and Indium doped $\mathrm{ZnO}$ films, respectively. So that the best estimation was found at the Indium doped $\mathrm{ZnO}$ thin with maximum enhancement of minimum errors were limited to 3.5 and $9.7 \%$ for the band gap and the Urbach energies, respectively. The decreases in the relative errors of undoped to Indium doped films can be explained by the fewer defects and less disorder.

10. S. Benramache, B. Benhaoua, N. Khechai, F. Chabane, Matériaux \& Techniques 100 No 6-7, 573 (2012).

11. W.L. Guan, J. Lian, Y.X. Yu, Z.Z. Sun, M.L. Zhao, X. Wang, W.F. Zhang, Optik 125 No 18, 5167 (2014).

12. S. Zhao, L. Yang, Y. Zhou, K. Zhaoa, Optik 122 No 11, 960 (2011).

13. C.C. Ting, C.H. Li, C.Y. Kuo, C.C. Hsu, H.C. Wang, M.H. Yang, Thin Solid Films 518 No 15, 4156 (2010).

14. R.E. Marotti, P. Giorgi, G. Machado, E.A. Dalchiele, Sol. Energ. Mater. Sol. C. 90 No 15, 2356 (2006).

15. J. Ramesh, G. Pasupathi, R. Mariappan, V. Senthil Kumar, V. Ponnuswamy, Optik 124 No 15, 2023 (2013).

16. S. Kushwaha, L. Bahadur, Optik 124 No 22, 5696 (2013).

17. S. Benramache, B. Benhaoua, Superlattices Microstruct. 52 No 6, 1062 (2012).

18. S. Benramache, O. Belahssen, A. Guettaf, A. Arif, J. Semiconductor. 34 No 11, 113001 (2013).

19. A. Gahtar, S. Benramache, B. Benhaoua, F. Chabane, J. Semiconductor. 34 No 7, 073001 (2013).

20. B. Benhaoua, A. Rahal, S. Benramache, Superlattices Microstruct. 68, 38 (2014). 
21. F. Chouikh, Y. Beggah, M.S. Aida, J. Mater. Sci.: Mater. Electron. 22 No 5, 499 (2011)

22. N. Zebbar, Y. Kheireddine, K. Mokeddem, A. Hafdallah, M. Kechouane, M.S. Aida, Mater. Sci. Semiconductor Proc. 14 No 3-4, 229 (2011).

23. S. Ilican, Y. Caglar, M. Caglar, F. Yakuphanoglu, Physica E 35 No 1, 131 (2006).

24. A. Rahal, S. Benramache, B. Benhaoua, Enginee. J. 18 No 2,81 (2014).
25. B.L. Zhu, X.H. Sun, X.Z. Zhao, F.H. Su, G.H. Li, X.G. Wu, J. Wu, R. Wu, J. Liu, Vacuum 82 No 5, 495 (2008).

26. S. Benramache, B. Benhaoua, Superlattices Microstruct. 52 No 4, 807 (2012).

27. A. Hafdallah, F. Yanineb, M.S. Aida, N. Attaf, J. Alloy. Compnd. 509 No 26, 7267 (2011).

28. S. Benramache, B. Benhaoua, H. Bentrah, J. Nanostruct. Chem. 3, 54 (2013).

29. S. Benramache, B. Benhaoua, O. Belahssen, J. Chem. Mater. Res. 4 No 1, 19 (2015) 